\title{
Impact of Social Media in the Fight Against Misinformation on
}

\section{Corona Virus Pandemic}

\author{
Joshua-Luther Ndoye Upoalkpajor \\ Department of Counselling Psychology, University of Education - Winneba, Post Office Box 25, Winneba, \\ Ghana. \\ jlnupoalkpajor@uew.edu.gh
}

\begin{abstract}
This study examined the impact of social media within the fight against misinformation on coronavirus pandemic. The study therefore assessed the character of coronavirus pandemic information shared on social media sites by undergraduate students in central region of Ghana. Structured questionnaire copies were administered to 355 undergraduate students in University of Education, Winneba, University of Cape Coast, and Cape Coast Technical University. Data was analyzed using descriptive and inferential statistics. Result showed that $71.3 \%$ of the scholars across the chosen universities were conscious of social media and made used of it. Facebook was the foremost favourite social media platform followed by Instagram and WhatsApp, while Kinschat, LinkedIn, Skype and BBM were least preferred social media sites. Independent samples test result showed there was no significant gender difference within the preference of social media sites $(\mathrm{t}=1.039, \mathrm{p}>0.05)$. The result showed that $81.4 \%$ of the scholars had encounter coronavirus pandemic information on social media, while only $24.8 \%$ had shared coronavirus pandemic information on social media. Prevention methods and general coronavirus pandemic knowledge were the most sorts of information shared. ANOVA result further revealed significant variation within the sort of coronavirus pandemic information shared on social media among the three universities $(F=5.177 ; p<0.05)$. The Post Hoc Test of multiple comparison indicated that the type of coronavirus pandemic information shared in Cape Coast Technical University differed significantly from those shared in University of Education, Winneba and University of Cape Coast respectively.
\end{abstract}

Keywords: SOCIAL MEDIA, MISINFORMATION, CORONA VIRUS PANDEMIC

DOI: $10.7176 / \mathrm{NMMC} / 95-05$

Publication date: February $28^{\text {th }} 2021$

\section{Introduction}

The wave of coronavirus (COVID-19)-related content has become a high-stakes test for social media platforms' abilities to fight misinformation. False recommendations about how to avoid contracting the virus or what measures infected people should take to avoid spreading it have the potential to cause more sickness and death from a pandemic that has already taken thousands of lives worldwide (World Health Organisation (WHO), (2020).

According to data from social media analytics platform Sprinklr, there were more than 19 million mentions related to COVID-19 across social media, blogs and online news sites worldwide on March 11, 2020. For context, mentions of US President Donald Trump on the same day came in at roughly 4 million. Many of the COVID-19 mentions likely came from legitimate sources, but given the novelty of the disease and the fast-changing nature of related news, it's safe to assume that a large portion was inaccurate or outdated.

The current battle against misinformation on most social media platforms is primarily concentrated on so-called "bad actors" that deliberately spread lies and misleading information, sometimes for political gain. Facebook, for example, uses an automated system to serve potentially inaccurate content to third-party fact-checkers who then identify, review and rate inaccurate stories so that their distribution can be reduced. It's a resource-heavy and timeconsuming process, and questions about its effectiveness were raised before the coronavirus conversation exploded on social media.

Khoros (2020) emphasized social media as the collection of tools and online space, available to help individual and business to accelerate their Information and Communications needs. Platforms like Twitter and Facebook were also among the earliest sources of accurate COVID-19 information. But since average citizens, celebrities, politicians and others use social platforms to share their coronavirus experiences, air grievances and simply kill 
time while self-isolating, important health and safety information easily gets drowned out. Many users may be well-meaning but uninformed, and they could be unintentionally spreading inaccurate information.

As a result, social media platforms have taken unprecedented steps to stop the spread of coronavirus-related misinformation. Facebook has provided the World Health Organisation (WHO) with as many free ads as they need and blocked ads from brands that may be exploiting the situation by claiming that their products can cure the virus, for example. That's in addition to increased fact-checking and a pop-up that directs users who search for coronavirus directly to the World Health Organization's website or a local health authority. Twitter also directs users to local health authorities' sites like the Centers for Disease Control and Prevention (CDC) in the US.

The major social platforms; Facebook, LinkedIn, reddit, Twitter and YouTube along with Google and Microsoft, issued a joint statement announcing that they had banded together to fight COVID-19-related misinformation.

The social media exist to service the information needs of the society, but at the same time, the noted problem is that most Information's are not from a reliable source, or is not credible. In line with the social responsibility role of the press,

Ferguson (2002) argued that most discussions we hold today originate their topics from broadcast media. Most social media subscribers neglect stories happening in the country and are more concerned with entertainment, this has made cultural imperialism affect the Nation as the use of smart phone affect the perception on the way, we think act and Behave in our respective lifestyle in Ghana, indicating that many people read and watch news they do not trust. Because News information is gotten from mistrust individuals, due to that fact anyone can disseminate news information at any point in time. Since reported levels of trust in media, are relatively low it is obvious that some people will watch news they say they do not trust while trying to filter out information, therefore they're considered biased or untrustworthy (WHO), (2020).

The main objective of the study is to research the impact of social media within the fight against misinformation on coronavirus pandemic.

1. What are the most social media platforms used to curb the spread of faux information of COVID-19?

2. What are the varied misinformations on COVID-19 and thus the simplest ways to stop the spread through the internet?

3. What is the general public perception of social media contribution within the fight against fake information on covid-19 in Ghana?

\subsection{Impact of faux News on Public Health}

Fake news concerning health on social media represents a risk to global health. the earth Health Organisation warned in February in 2020 that the COVID-19 outbreak had been amid an enormous 'infodemic', or an overabundance of information - some of which was accurate and a couple of of which was not-which made it difficult for people to hunt out reliable sources and trustworthy information once they needed it. The results of disinformation overload are the spread of uncertainty, fear, anxiety and racism on a scale not seen in previous epidemics, like SARS, MERS and Zika. Therefore, the earth Health Organisation is dedicating tremendous efforts aimed toward providing evidence-based information and advice to the population through its social media channels, like Weibo, Twitter, Facebook, Instagram, LinkedIn and Pinterest, also as through its website. The MIT Technology Review highlights that social media aren't only getting wont to spread false news and hate messages but are also getting wont to share important truthful data and solidarity with all those affected by the virus and hate messages. We are in what some have called the second information revolution. The first information revolution began with the spread of the word through the press. Now, during this second information revolution, a digital transformation is shaping how citizens around the world interact with each other. We face an unprecedented global expansion within the ways we share, access and make information that's presented in many formsone of which is social media Ferguson (2002).

From diverse fields of knowledge linked to health issues, it are often stated that social media can have both a positive and a negative impact on public health. On the one hand, the mixture of AI and enormous data can help public health providers identify pandemic diseases in real time, improving the coordination of the response of public health systems through information sharing and improving surveillance and diagnostics. Furthermore, research shows that social media information and social media responses are effective strategies to understand feedback on potential public health policy proposals. This positive impact of social media in health has been demonstrated during a recent study about heat protection policy for Australian 
schools, which, through the analysis of public comments posted on a national Australian Broadcasting Corporation $(\mathrm{ABC})$ website, identifies the themes to support a national heat protection policy for schools (Economic and Social Research Council - UK, 2020). There is evidence of the negative effects of using social media to spread misinformation, which produces harmful consequences to global health and wellbeing, becoming one of the simplest challenges for public health systems today. The foremost extensively studied topics involving misinformation in health are vaccination, Ebola and thus the Zika virus, also as nutrition, cancer, the fluoridation of water and smoking. Disinformation spread by the anti-vaccine movement has led to episodes regarding vaccination provoking easily preventable disasters, just like the measles epidemic in Washington State (WHO 2019). The spread of false information also explains a decrease in immunization behaviors with regard to measles-mumps-rubella vaccinations, explaining the drop in the demand for this vaccine within the United Kingdom and thus the USA between 1999 and 2000 .

Furthermore, research related to the negative impacts linked to the authenticity of social media and identities has increased in recent years.

\subsection{Spreading Fake News on Health in Social Media}

\subsubsection{The context during which fake news is spread}

Never before in human history has the role of globalization processes had the impact that it currently has in decision-making processes and societies thanks to the speed of communication. Globalization also plays a crucial role within the spread of health news, including social media, influencing the way users receive such news. During this arena, it is vital to spotlight that in a globalized world, health content information are often perceived differently relying on the target group or context. Therefore, fake news may reach citizens in several ways, relying on their age, culture, and other factors (Tandoc, Lim, \& Ling, 2018). Moreover, research shows that social media and related global digital media content influence discourses about professions and therefore the way citizens perceive them, including public health professionals. as an example, many public health programs aimed toward children and youth have education at the core of their initiatives. The teaching profession is typically portrayed in digital media in regard to unhelpful physical crisis messages or discourses related to bullying in movie scenes. During an identical vein, social media has also been demonstrated to influence the perceptions of adolescent students with regard to their sexual and reproductive health learning. As a result, health professionals may recognize that social media channels, such as Facebook, offer possibilities to support their activities (Lowell \& Bharat, 2012). Research on the role of mass media and messages and dominant discourses that are communicated to the public is an emerging topic of interest in scientific works that requires further investigation. The influence of social media discourses may differ depending on age, culture or gender. For example, young people build their identities, construct knowledge and acquire information from digital media, including social media, beyond formal education and classroom learning, which an approach is resonating with "public pedagogies". Other authors such as Ulmer argue that mass digital media provides the public an 'entry point' into the debates. The fact is that digital and social media contribute to the strength or undermine the diversity of points of view, influencing the development of specific health public health policies and interventions. Such influence of the media has been defined by some authors as the "fourth state". Taking into account these contextual considerations, it is important to face fake news related to health in social media to support public health policies instead of trying to reverse them (Waszak, Kasprzycka-Waszak \& Kubanek, 2018).

\subsubsection{Fake News, Health and Social Media}

In a globalized world, the spread of fake news content on health-related topics in social media and the ways in which it spreads have recently been discussed in-depth. Misinformation and disinformation-misinformation as inaccuracy and errors and disinformation as a falsehood created on purpose and the spread of it by malicious individuals (human or bots) _ gain momentum from the desire to find a solution to a particular disease or illness by patients or their relatives, who inadvertently contribute to spreading misleading information (Bruno Kessler Foundation, 2020). Globally, the narratives of misinformation are dominated by personal, negative, and opinionated tones, which often induce fear, anxiety, and distrust of institutions. Once misinformation gains acceptance in such circumstances, it is difficult to correct, and the effectiveness of interventions varies according to the personal involvement of each individual and his or her literacy and sociodemographic characteristics. 
However, other studies have shown that ignorance rarely leads to strong support for a cause. For example, those who most strongly reject the scientific evidence of climate change are also those who believe that they are best informed about the issue. People's pre-existing attitudes often determine their level of belief in misinformation (UN, 2020). With respect to globalization processes, evidence suggests that false information spreads globally more pervasively and farther and faster than the truth spreads in social media. In examinations of possible explanations for this global phenomenon, it has been found that novelty is a pervasive component of false rumors, which are significantly more novel than the truth. However, data cannot support the contention that novelty is the only reason, or the main reason, for the spreading of falsehood. However, other studies that have focused on the analysis of fake news in social media have reached different conclusions. A recent study that analyzed the credibility of sources publishing articles online that may reach global audiences concludes that for the specific case of online health information and content on social media, people are more concerned about the veracity and credibility of the information source and tend to spread less misinformation about health. One possible explanation given by the authors is that people generally do not read health information for entertainment but rather search for information useful to their health or that of people close to them. Furthermore, in these cases, they are less likely to have a pre-existing opinion about health information than are those who share fake news stories about other topics. A similar conclusion came from a fact-checking study of Twitter and Sina Weibo (the most-used social media platform in China), developed 24 hours after the World Health Organisation's declaration of the Ebola outbreak as a Public Health Emergency of International Concern in August 2014. In a globalized world, this declaration by the World Health Organisation had diverse impacts on the definition of private and public strategies to combat the virus. It contended that only $2 \%$ of the posts created on Twitter and Weibo were fake news or disinformation, while the rest were outbreak-related news and scientific health information, mostly coming from news disinformation, while the rest were outbreak-related news and scientific health information, mostly coming from news agencies reporting information from public health agencies. This study was able to confirm that these two social media sources contributed to spreading the news of the Ebola outbreak, which was the key message of the World Health Organisation. Research on fake news on health in social media covers a variety of channels, including Twitter, Facebook, Reddit, and Weibo. The analysis of Twitter has gained special attention, and research shows the reach of Twitter codes and the manner in which information spreads on Twitter. This occurs in diverse fields related to public health, from physical education to healthy eating habits or healthy lifestyles (Tandoc, Lim, \& Ling, 2018).

\subsection{Identification of Social Media Interactions as Key to Spreading or Combating Health-Related Fake News}

Social interaction appears to be the main method of understanding how disinformation or fake news spreads over social media. Different studies have been conducted to identify by who and how health disinformation content is promoted in social media. Within the case of Twitter, differing types of malicious actors covering both automated accounts (including traditional spam bots, social spam bots, content polluters, and fake followers) and human users, mainly trolls, are identified

It is very difficult to detect whether there's a person's or a bot behind a profile. However, all of them produce distorting effects which will be critical to messages from public health systems (Cinelli et al, 2019). One among the studies within the case of vaccines identified three sorts of profiles that had a special probability of spreading vaccine-related disinformation. The primary profile is trolls, or Twitter accounts with real people behind them, identified from lists compiled by U.S. authorities; these trolls use the hash tag \#VaccinateUS and spread pro- and anti-vaccination messages, often with the apparent aim of encouraging people to believe that the medical community is divided. The second profile, called 'sophisticated bots', is AI that automatically spreads content via Twitter with an equivalent objective of making people believe that the medical community is divided. The third group of profiles is comprised of content polluters, who use anti-vaccine messages to pique users' curiosity and lead them to click on links; such every click leads to more income for those behind the web site. Some studies have suggested the necessity to extend social media literacy, provide strategies and instruments to check the reputation, consistency, and evidence of any information, and avoid self-confirmation (based on assumptions or previous unchecked experiences).

\subsection{Combating Fake News on Social Media}

Several approaches are proposed in recent years to automatically assess credibility in social media. Most of them are supported data based models, i.e., they use automatic learning techniques to spot misinformation. Based on these techniques, different applications are developed with different objectives

and in several contexts, like detecting opinion spam on review sites, detecting false news and spam in microblogging, and assessing the credibility of online health information. 
These techniques include both human intervention and algorithms to verify the veracity of data across technologies, like AI and tongue. Other mechanisms developed as a remedy against fake news on social media are source ratings which will be applied to articles once they are initially published, like expert ratings (in which expert reviewers fact check articles - the results of which are aggregated to supply a source rating), user article ratings (in which users rate articles-the results of which are aggregated to supply a source rating), and user source ratings (in which users rate the sources themselves) (Antino \& Alan, 2019).

According to the literature, social media is an interaction context in which misinformation is spread faster, but at the same time, there are interactions focused on health that are evidence based. Furthermore, it is important to highlight that social media users share the social impact of health research.

\subsection{Overview of Coronavirus}

Coronavirus disease 2019 (COVID-19) is an emerging respiratory disease that's caused by a completely unique coronavirus and was first detected in December 2019 in Wuhan, China (Upoalkpajor \& Upoalkpajor, 2020). The disease is very infectious, and its main clinical symptoms include fever, dry cough, fatigue, myalgia, and dyspnea. In China, $18.5 \%$ of the patients with COVID-19 develop to the severe stage, which is

characterized by acute respiratory distress syndrome, septic shock, difficult-to-tackle acidosis, and bleeding and coagulation dysfunction (Harapana et al, 2020).

The first infected patient who had clinical manifestations like fever, cough, and dyspnea was reported on 12 December 2019 in Wuhan, China. Since then, 2019-nCoV has spread rapidly to other countries via alternative ways like airline traveling and now, COVID-19 is that the world's pandemic problem (Wuhan, 2019). Coronaviruses (CoV) infections are emerging respiratory viruses and known to cause illness ranging from the cold to severe acute respiratory syndrome (SARS) (Tian et al., 2020). CoV is zoonotic pathogens which will be transmitted via animal-to-human and human-to-human.

Multiple epidemic outbreaks occurred during 2002 (SARS) with 800 deaths and 2012 (Middle East Respiratory Syndrome: MERS-CoV) with 860 deaths (Luo \& Gao, 2020). Approximately eight years after the MERS-CoV epidemic, the present outbreak of novel coronavirus (COVID-19) in Wuhan City, Hubei Province of China, has emerged as a worldwide outbreak and significant public health issue. On 30 January 2020, the planet Health Organisation declared COVID-19 as a public health emergency of international concern. Astonishingly, within the first week of March, a devastating number of latest cases are reported globally, emerging as an epidemic .As of 9 March 2020, quite 110,000 confirmed cases across 105 countries and quite 3800 deaths are reported (Singhal, 2020). The COVID-19 is spread by human-to-human through droplets, feco-oral, and direct contact, with any time period of 2-14 days. So far, no antiviral treatment or vaccine has been recommendedexplicitlyforCOVID-19. Therefore, applying the precautions to regulate COVID-19 infection is that the utmost critical intervention. Healthcare workers (HCWs) are the primary section in touch with patients and are an important source of exposure to the infected cases within the healthcare settings, thus, expected to be at a high risk of infections. By the end of January, the World $\mathrm{HO}$ and CDC (Centers for Disease Control and Prevention) have published recommendations for the prevention and control of COVID-19 for HCWs. Indeed, the World Health Organisation also initiated several online training sessions and materials on COVID-19 in various languages to strengthen the preventive strategies, including raising awareness, and training HCWs preparedness activities (Prajapat et al, 2020). In several instances, misunderstandings of HCWs delayed controlling efforts to provide necessary treatment, implicate rapid spread of infection in hospitals, and also may put the patients' lives at risk. In this regard, the COVID-19 epidemic offers a unique opportunity to investigate the level of knowledge, and perceptions of HCWs during this global health crisis. Besides, we also explored the role of different information sources in shaping HCWs knowledge and perceptions on COVID-19 during this peak period. It seems that the current widespread outbreak has been partly associated with a delay in diagnosis and poor infection control procedures. As transmission within hospitals and protection of healthcare workers are important steps in the epidemic, the understanding or having enough information regarding sources, clinical manifestations, transmission routes, and prevention ways among healthcare workers can play roles for this assessment. Since nurses are in close contact with infected people, they are the main part of the infection transmission chain and their knowledge of 2019-nCoV prevention and protection procedures can help prevent the transmission chain. Iran is one of the most epidemic countries for COVID-19 and there is no information regarding the awareness and attitude of Iranian nurses about this infectious disease. 


\subsection{The virus, its origins and evolution}

Coronavirus is believed to be transmitted through respiratory aerosols, which were released while SARS patient coughs or sneezes. Viral infection will spread from the droplets of cough or sneeze of an infected patient are propelled in surroundings via air and will infect the nearby people who are nearby through several ways like mouth, nose or eyes. The virus also can spread by touching infected surfaces, and then touching the mouth, nose, or eye (Centers for Disease Control and Prevention, 2020). Severe acute respiratory syndrome (SARS) probably first emerged in Guangdong around November 2002. Many of the affected individuals in November and December 2002 had contact with the live-game trade. The disease was described as an "infectious atypical pneumonia" because of its propensity to cause clusters of disease in families and healthcare workers. The etiological agent of SARS was identified as a new coronavirus not previously endemic in humans. The lack of serological evidence of previous infection in healthy humans suggested that COVID-19 had recently emerged in the human population and that animal-to-human interspecies transmission seemed the most probable explanation for its emergence. Specimens collected from apparently healthy animals (e.g., Himalayan palm civets (Paguma larvata) and raccoon dogs (Nyctereutes procyonoides)) found in live wild-game animal markets in Guangdong yielded a COVID-19like virus with more than $99 \%$ nucleotide homology to the human COVID-19. But the wild-animal reservoir in nature still has not been identified conclusively. Many workers who handled animals in these wet markets had anti body to the related animal COVID-19-likevirusalthough they had no history of a SARS-like disease. Taken together with the observation that a number of the SARS-affected individuals in November and December 2002 had epidemiological links to the wild-game animal trade, it is likely that these wet markets in Guangdong provided the interface for transmission to humans (Peiris \& Guan, 2004). They further explain that the early interspecies transmissions to humans were probably inefficient, causing little human disease or transmission between humans. Eventually, the animal precursor COVID-19-like virus probably adapted to more efficient human-to-human transmission, and Coronavirus emerged. As two authors aptly stated, this was "one small step to man, one giant leap to mankind".

\subsection{Epidemiology}

Fifty-three percent of probable cases of Coronavirus reported to the World Health Organization were female, and all age groups were affected (age range 0-100 yrs). Worldwide, Coronavirus was strikingly a nosocomially acquired infection. Health care workers comprised $22 \%$ of reported cases in Hong Kong and Guangdong, China and $>40 \%$ in Canada and Singapore. A complex mix of agent, host-biologic, and behavioral factors and environmental context determine the magnitude and spread of outbreaks. Not all cities or countries that received even the earliest Coronavirus importations experienced sustained transmission or outbreaks (WHO, 2020).For example, in Canada, (the Greater Toronto Area, Ontario and the city of Vancouver), British Columbia received critically ill patients from the Hotel Mcluster. Whereas the Greater Toronto Area experienced an extensive outbreak, no secondary spread ensued from the case in Vancouver. Similarly, no sustained transmission occurred in the United States despite multiple importations. Why some areas experienced sustained outbreaks and others did not have yet to be fully explained. SARS remained isolated in China from November 2002 until 21 February 2003, when a physician with SARS traveled from Guangdong to a hotel in Hong Kong, infecting 10 other guests. The movements of these 11 individuals resulted in the spread of SARS worldwide and sparked all of the major epicenters outside of China.

The rate of spread of a plague and whether it's self-sustaining depend upon the essential reproduction number. Reproduction number is defined as the average number of secondary cases generated by 1 primary case in a susceptible population. This quantity determines the potential for an infective agent to start out an epidemic, the extent of transmission within the absence of control measures, and therefore the ability of control measures to reduce spread. During the course of a plague, Rt, the effective reproduction number, decreases as compared with $\mathrm{R} 0$ as a results of the depletion of susceptible persons within the population, death or recovery with subsequent immunity, and the implementation of specific control measures. To stop an epidemic, Rt must be maintained below 1. Mathematical modeling of the first phase of the Singapore and Hong Kong outbreaks, before the institution of control measures and through which era it had been occurring primarily within the hospital setting, estimated that the R0 was $2.2-3.7$, indicating that the virus is moderately infective. The attack rate for COVID-19 ranges from $10.3 \%$ to $60 \%$ or 2.4 to 31.3 cases/1000 exposure-hours, depending on the clinical setting and the unit of measurement. A significant limitation of these calculations is that these data are based on diagnoses made with a clinical case definition. 
Reanalysis will be required once the results of seroprevalence studies are completed and will provide a more accurate estimate of R0 (Rothman, Las \& Greenland).

1.7.1 Incubation Period

The estimated incubation period for Coronavirus is $2-14 \mathrm{~d}$. An incubation period of as low as $1 \mathrm{~d}$ was reported from China (four cases) and Singapore (three cases). Incubation periods of 10-14 days have been reported in a small number of cases from China, but case ascertainment and a well-defined exposure interval for these cases are incomplete. Most countries reported a median time period of 4-5 days and a mean of 46 days. It remains unclear whether the route of transmission influences the incubation period (WHO, 2020). 1.7.2 Infectious Period

There has been no evidence to date of COVID-19 transmission prior to symptom onset, and transmission from asymptomatically infected persons has not been observed. There have been no reports of transmission beyond 14 days of fever resolution. Transmission appears to be greatest from severely ill patients and people experiencing rapid clinical deterioration, usually during the second week of illness. Patients with Coronavirus are most infectious at around day 10 of illness. In this regard Coronavirus is unlike most other respiratory-borne diseases, with the notable exception of smallpox.

\subsection{Etiology}

Droplets from coughing and sneezing and close human contact likely transmit the Coronavirus. The respiratory droplets are probably absorbed into the body through the mucous membranes of the mouth, nose, and eyes.

This could be through:

1. Body contact

2. Sharing utensils for eating and drinking

3. Speaking to someone within a distance of 3 feet

A person with the virus can spread the infection by leaving respiratory droplets on objects, like door handles, doorbells, and telephones. These are then picked up by someone else. The virus is likely to remain active in the environment for several days (Liu et al, 2020).

\subsection{Signs and symptoms}

Incubation period of the COVID-19 ranges from 2 to 14 days. Signs and symptoms include: high fever, migraine, and discomfort in respiration and body pains, slight respiratory problem, diarrhea (10-20\%), and cough (after 2-7 days) (Lee et al, 2003).

\section{Materials and Methodology}

The study employed the descriptive cross sectional survey design to collect detailed and factual information on the subject of investigation. The data for this study were generated from two main sources; Primary sources and secondary sources. The primary sources include questionnaire, interviews and observation. The secondary sources include journals, bulletins, textbooks and the internet.

The multi-stage sampling technique was employed. In the first stage, using purposive sampling technique to select University of Education, Winneba (UEW), University of Cape Coast (UCC), and the Cape Coast Technical University (CCTU) based on their familiarity in the central region. In the second stage, all undergraduate students were selected using stratified sampling technique. In the fourth stage, systematic sampling method was employed to administer the structure questionnaire to students across the three universities. In order to ascertain the exact number of students to sample or administer questionnaire, the total population of undergraduates in University of Education, Winneba (UEW), University of Cape Coast (UCC), and the Cape Coast Technical University (CCTU) were obtained from the Admission Office in the three universities. Fisher et al. (1983) formula was wont to determine the sample size. Similar formula was employed by Ndeti (2013) as follows:

$\mathrm{N}=\mathrm{Z}^{2} \mathrm{pg} / \mathrm{d}^{2}$

Where $\mathrm{n}=$ the specified sample size, when the target population is quite more than $10,000 \mathrm{Z}=$ is standard normal deviate at the specified confidence level (1.96) at 0.05 .

$\mathrm{p}=$ is the proportion of the target population estimated to have the characteristics being measured when one is not sure, so one takes middle ground $(0.5)$.

$\mathrm{q}=1-\mathrm{p}$

$\mathrm{d}=$ is the level of statistical significance

Therefore, $\mathrm{n}=384$. 
The calculation indicated that 384 undergraduates would be sampled. Hence, the distribution of questionnaire was done in relation to the population of undergraduate students in the respective schools. University of Cape Coast was administered 141 questionnaire copies, Cape Coast Technical University had 118 questionnaire copies and University of Education Winneba had 124 questionnaire copies. At the top of questionnaire administration, out of the 384 questionnaire copies distributed, 355 copies were successfully collected, collated and deemed suitable to be used.

2.1 Data collection and analysis

The structured questionnaire was personally administered with assistance of two trained research assistants. Data gathered were analysed using tables, simple percentages; bar chart, One-Way Analysis of Variance (ANOVA) and Independent Samples Test were employed to analyze the quantitative data.

\section{Result and Discussion}

\subsection{Demographic characteristics of respondents}

The demographic result indicated that $60.3 \%$ of the respondents were males (Table 1 ). The result obtained lends support to the finding of Idubor (2015) who reported male undergraduate students' dominance of $71.7 \%$ in social media use and addiction. The age distribution indicated that majority $(89.0 \%)$ of the respondents within the three universities fell within the ages of $17-22 \mathrm{yrs}$; implying that majority of the scholars surveyed in the three universities are adolescents. Similar age range was reported by Idubor (2015) where undergraduates aged 16 -20yrs were identified to constitute majority of the age cohorts of the study. The religion of respondents identified Christianity and Islam because the widely and commonly practiced religion by $99.4 \%$ of the respondents (Table 1). It however showed that an honest number of the respondents within the three universities were Christians, followed by Islam with traditional worshippers and atheists being unpopular religion. The study showed that $100-300$ level making up $80.3 \%$ dominated the survey and this category of scholars are believed to form most use of social media platforms (Table 1). It further showed that in University of Education, Winneba and University of Cape Coast, 100 level students were most dominant, while 200 level students were dominant in Cape Coast Technical University. In all, the extent of scholars shows that an honest number of the scholars are at their early and near- stage of completion of their education. The result obtained is discrepant with the study of Swidan et al., (2013) where 300 and 400 level students dominated the survey.

Social media awareness and its influence on use

Social media is the 21 st Century global phenomenon and breakthrough in telecommunication that enables people to connect with one another, share information, pictures and other valuable information irrespective of geographic distance. The awareness of social media is overwhelming as such; people (both young and adults) have seen the necessity to be connected there to. Mangold et al., (2009) stated that social allows for the commenting, critiquing, sharing and knowledge possible on a good scope and in some cases in real time. The relevance of social media has made many people worldwide to shop for Smart-phones with operating systems that enable social media sites to be installed and used for diverse purposes. The end in Table 2 shows the extent of awareness of social media and therefore the usage. The result showed that the worldwide awareness of social media had enabled majority of the scholars to form use of social media. This is apparent as students cannot do without social media which has helped them to attach with friends, make friends and upload pictures among others.

The result obtained above corroborates the finding of Musa et al., (2015) that majority (98.2\%) of the scholars of Kano State polytechnic in Nigeria is conscious of social networks and regularly use it. Despite, the increased awareness on the importance of the e-telecommunication medium, not all the scholars were ready to use it. This is the case as $28.7 \%$ of the scholars affirmed to not use. In all, the result implies increase within the proportion of scholars using social media which is attributed to the notice the scholars wear the importance of using it. Several reasons may be responsible for students' inability to make use of social media. One of such reason is money. Many of the Smart-phones are costly which are beyond the reach of some students. This can cut them off from using social media platforms even when they are aware of its importance. However, the proportion of students across the universities that make use of social media alleged that it enables them to interact, exchange ideas and inform peers on coronavirus pandemic. Informing peers on coronavirus pandemic is the third reason why students use social media. It means therefore that only few students' use social media to enable them inform their peers about coronavirus pandemic. Kaplan and Haenlein (2010) stated that through the use of social media pertinent information on coronavirus pandemic can be shared among peers. 
Table 1: Demographic and Socio-economic characteristics of respondents

\begin{tabular}{|c|c|c|c|c|c|c|c|}
\hline \multirow{4}{*}{ Variables } & \multicolumn{4}{|c|}{ Universities } & \multicolumn{2}{|c|}{ Total } & \\
\hline & \multicolumn{2}{|c|}{ UEW } & \multicolumn{2}{|c|}{ UCC } & \multicolumn{2}{|c|}{ CCTU } & \\
\hline & \multirow[b]{2}{*}{$\begin{array}{l}\text { Freq } \\
(\mathrm{n}=111)\end{array}$} & $\%$ & \multirow[b]{2}{*}{$\begin{array}{l}\text { Freq } \\
(\mathrm{n}=130)\end{array}$} & \multirow[b]{2}{*}{$\begin{array}{l}\% \\
(100)\end{array}$} & \multirow[b]{2}{*}{$\begin{array}{l}\text { Freq } \\
(\mathrm{n}=114)\end{array}$} & \multirow[b]{2}{*}{$\begin{array}{l}\% \\
(100)\end{array}$} & \\
\hline & & $\begin{array}{l}\% \\
(100)\end{array}$ & & & & & \\
\hline Sex of respondents & & & & & & & \\
\hline Female & 42 & 37.8 & 55 & 42.3 & 44 & 38.6 & 39.7 \\
\hline Male & 69 & 62.2 & 75 & 57.7 & 70 & 61.4 & 60.3 \\
\hline \multicolumn{8}{|l|}{ Ages of respondents } \\
\hline $16 \mathrm{yrs}$ & - & - & 1 & 0.8 & - & - & 0.3 \\
\hline $17-19 y r s$ & 56 & 50.5 & 83 & 63.8 & 59 & 51.8 & 55.8 \\
\hline $20-22 y r s$ & 52 & 46.8 & 39 & 30.0 & 27 & 23.7 & 33.2 \\
\hline $23-25 y r s$ & - & - & 2 & 1.5 & 3 & 2.6 & 1.4 \\
\hline$>25 \mathrm{yrs}$ & 3 & 2.7 & 5 & 3.8 & 25 & 21.9 & 9.3 \\
\hline \multicolumn{8}{|l|}{ Religion of respondents } \\
\hline Christianity & 63 & 56.8 & 82 & 63.1 & 63 & 55.3 & 58.6 \\
\hline Islam & 48 & 43.2 & 47 & 36.2 & 50 & 43.9 & 40.8 \\
\hline No religion & - & - & 1 & 0.8 & - & - & 0.3 \\
\hline Traditional worshippers & - & - & - & - & 1 & 0.9 & 0.3 \\
\hline \multicolumn{8}{|l|}{ Level of study } \\
\hline 100 Level & 32 & 28.8 & 64 & 49.2 & 30 & 26.3 & 35.5 \\
\hline 200 Level & 28 & 25.2 & 24 & 18.5 & 36 & 31.6 & 24.8 \\
\hline 300 Level & 28 & 25.2 & 26 & 20.0 & 17 & 14.9 & 20.0 \\
\hline 400 Level & 20 & 18.0 & 10 & 7.7 & 29 & 25.4 & 16.6 \\
\hline 500 Level & 3 & 2.7 & 6 & 4.6 & 2 & 1.8 & 3.1 \\
\hline
\end{tabular}

Nevertheless, the main reason for the use of social media is for interaction. This is glaring as majority of the students buy or wishes to own Smart-phones to enable them install social media sites and keep interacting with their friends, lovers and peers. Issues related to coronavirus pandemic are not the prominent reasons for the use of social media or put differently, the awareness on coronavirus pandemic is not the chief reason for students' use of social media. The information in Table 2 therefore has it that majority of the scholars across the chosen universities make use of social media because they're fully conscious of it. It further shows that the notice on interaction and exchange of ideas are the 2 principal reasons for using social media. This result pays credence to the submission of Tukru and Abdukadir (2013), once they identified communicating with friends, getting information about people, events and entertainment among others because the main reasons university students in Turkey use social media platforms like Facebook. In the same way, it agrees with the finding of Dlamini et al., (2015) that university students are conscious of social media and that they use it to interact with friends and loved ones also as share ideas and messages among others. 
Table 2: Awareness and increased use of social media

\begin{tabular}{|c|c|c|c|c|c|c|c|}
\hline \multirow[t]{3}{*}{ Variables } & \multicolumn{6}{|c|}{ Universities } & \multirow{3}{*}{$\begin{array}{c}\text { Total } \\
\%\end{array}$} \\
\hline & \multicolumn{2}{|c|}{ UEW } & \multicolumn{2}{|l|}{ UCC } & \multicolumn{2}{|c|}{ CCTU } & \\
\hline & $\begin{array}{c}\text { Freq } \\
(\mathrm{n}=111)\end{array}$ & $\begin{array}{c}\% \\
(100)\end{array}$ & $\begin{array}{c}\text { Freq } \\
(\mathbf{n}=\mathbf{1 3 0})\end{array}$ & $\begin{array}{c}\% \\
(100)\end{array}$ & $\begin{array}{c}\text { Freq } \\
(\mathrm{n}=114)\end{array}$ & $\begin{array}{c}\% \\
(100)\end{array}$ & \\
\hline \multicolumn{8}{|l|}{ Awareness and use of social media } \\
\hline Yes & 84 & 75.7 & 88 & 67.7 & 81 & 71.1 & 71.3 \\
\hline No & 27 & 24.3 & 42 & 32.3 & 33 & 28.9 & 28.7 \\
\hline \multicolumn{8}{|l|}{ If Yes, the ways it has } \\
\hline Not applicable & 30 & 27.0 & 42 & 32.3 & 30 & 26.3 & 28.7 \\
\hline It has increased interaction & 23 & 20.7 & 43 & 33.1 & 30 & 26.3 & 27.0 \\
\hline $\begin{array}{l}\text { It has created a forum for exchange of } \\
\text { 1deas }\end{array}$ & 32 & 28.8 & 26 & 20.0 & 31 & 27.2 & 25.1 \\
\hline $\begin{array}{l}\text { It has informed peers about HIV and } \\
\text { AIDS }\end{array}$ & 18 & 16.2 & 14 & 10.8 & 8 & 7.0 & 11.3 \\
\hline $\begin{array}{l}\text { Awareness has increased knowledge } \\
\text { about HIV }\end{array}$ & 8 & 7.2 & 5 & 3.8 & 15 & 13.2 & 7.9 \\
\hline
\end{tabular}

Favourite social media platform used by undergraduates and choice of usage

The 21 st Century affords youths and young adults different social media platforms used for chatting and sharing information among other uses. The choice of those social media platforms varies with their simple use, popularity and data consumption among other reasons for such preference. The preferred or favourite social media platforms normally employed by undergraduates for diverse purposes are shown in Table 3. The result showed that Facebook was the foremost favourite social media platform employed by undergraduates within the three universities; this was closely followed by Instagram and WhatsApp (Figure 1). Kinschat, LinkedIn, Skype and BBM were identified as least preferred social media sites. It doesn't mean that these platforms aren't employed by the scholars, but they're not among the favourite sites frequently entered by students for diverse purposes. Facebook is used by students to share pictures, messages and make new friends.

This result lends support to the finding of Rosen (2010) who reported that Facebook constitutes the most important social media platform within the world, with over 80 per cent of a teenager's time normally spent on this platform. Also, Boyd and Ellison (2007) alleged that adolescents often make use of social media sites notably Facebook, Whatsapp, YouTube, and Twitter among others to create and maintain relationships with people. It also lends support to the study of Owusu-Acheaw and Larson (2015) who reported in their study that 66.2 per cent of the scholars found Facebook as their most favourite social media platform. Facebook enables people across different geographical locations to attach with each other. Indeed, many students spend much of their time on Facebook to comment, like and love their friends' post and every one that. As a result of it wide usage and users, Facebook has received immense attention from health information seekers who use the platform for health information dissemination; the information passed is then shared by students on their walls.

The sharing of health information on wall enables it to succeed in many youths mostly. The secondly mostly used social media platform was Instagram. This platform makes it possible for college kids to share messages, pictures and other necessary information. On this platform, pictures on health information are often posted or shared to make awareness. The third most preferred site was WhatsApp, and at present, it is used by students for basically chatting and information dissemination. However, with recent upgrade, the platform can now be used for the sharing of files. Nevertheless, these three social media platforms are mostly used by students in tertiary institution for chatting, sharing of pictures, messages and making of new friends. The information whether health related or otherwise shared on these social media sites can contribute substantially to attitudinal change. Mostly health information, when shared, it enables young individuals to be cautious of their behaviour and ways of association. In a related study, Hoffman \& Novak 
(2012) stated that social media platforms make it possible for information to be easily shared by users on demand also as increases the possibility of collecting and sharing information across geographical location.

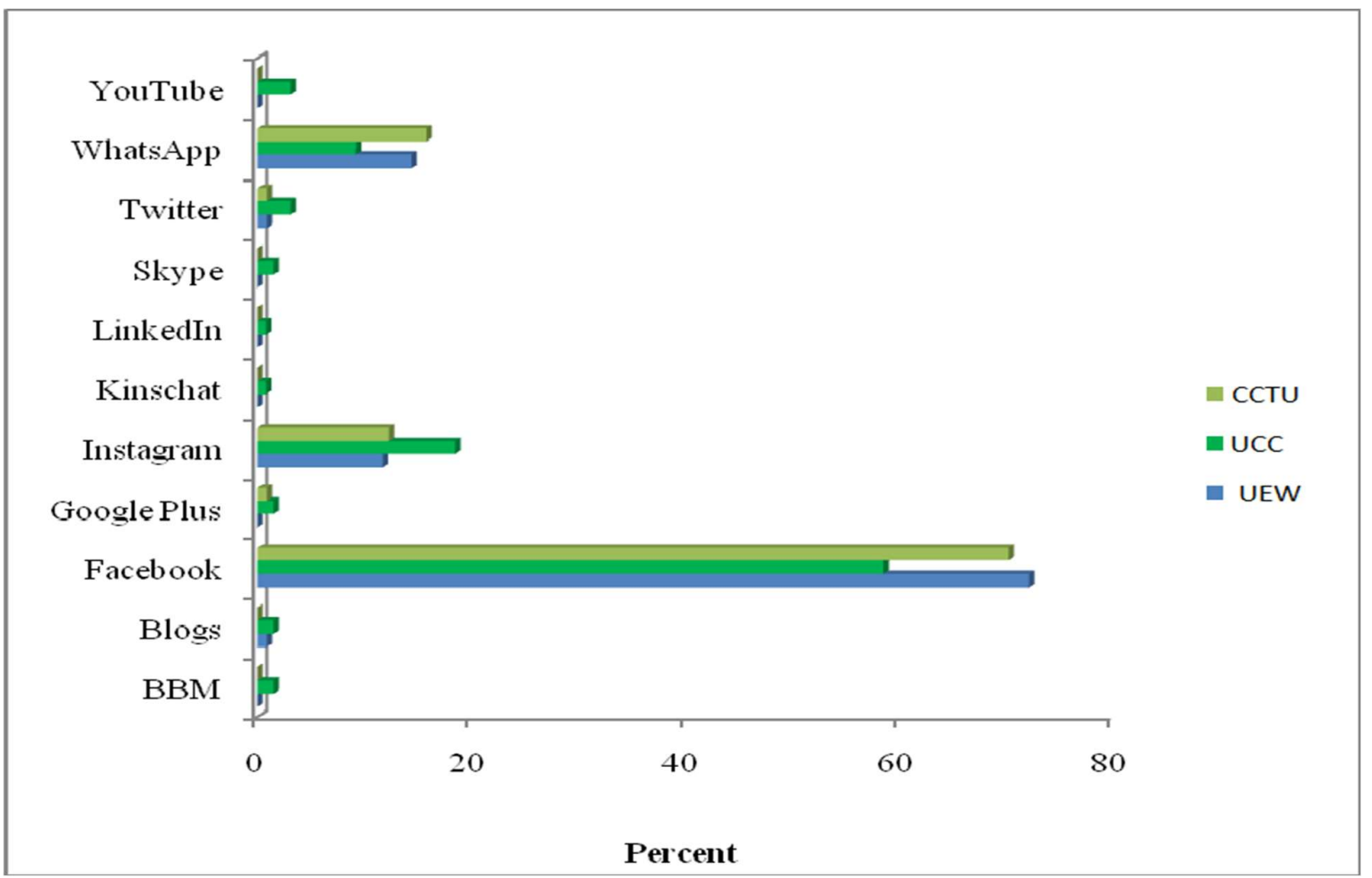

Figure 1: Favourite social media platforms

Similarly, Mangold and Faulds (2009) opined that users of these social media platforms with just a few of keystrokes are now able to share information with hundreds or thousands of fellows. The reasons given by the respondents for the preference of Facebook, Instagram and WhatsApp are presented in Table 3. The informative (educative) and straightforward use were the principal reasons given for the preference of these three social media sites over others. This is usually obvious because many educative messages and pictures are often easily shared on these platforms. Other significant or noticeable reasons for the choice above were making people less bored and peer influence (many people make use of these platforms because many of their friends, relatives, colleagues and loved ones use them intrinsically, they're going to easily attach with them). Abah et al. (2014) stated that Facebook is that the most well liked social media site. They further noted that social media sites are helpful in sharing health information and solving their health related problems. 
Table 3: Favourite social media platforms usually used by students

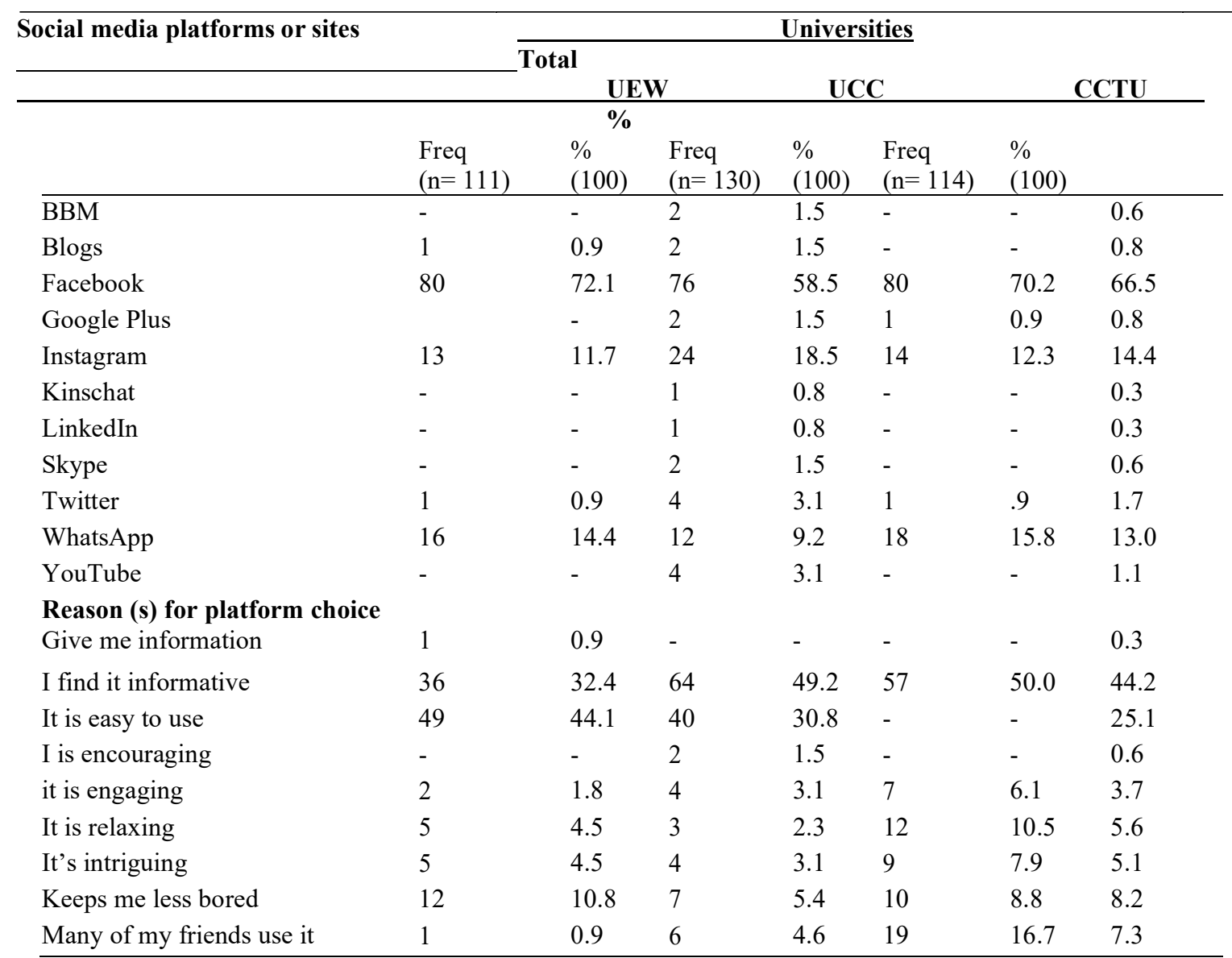

3.2 Gender assessment of favourite social media platform

Additional analysis was done to find out the favourite social media sites amongst male and female as well as to decide if preference of social media sites varies amongst gender. Mazman and Usluel (2011) agree that male and female social network users have ideal sites they often log onto to update their profiles, reflect on daily life, share information, maintain and establish social contacts and relationships, and facilitate provision of education. The information in Table 4 showed that Facebook, Instagram and WhatsApp were the most preferred social networking platforms used by both male and female users to accomplish the purpose mentioned above. Facebook is identified as the prominent social media sites mostly used by both sexes. This result pays substantial credence to the study of Pempek et al., (2009) and many others who identified Facebook and Twitter are most popular and commonly used by young adults of both gender. The Independent Samples Test result in Table 4 showed that the probability value of 0.299 is greater than $5 \%(0.05)$ significance level, which meant that there was no significant gender difference in the preference of social media sites $(t=1.039, p>0.05)$. This is apparent as the listed social media sites are used by both males and females for different purposes. In a related study, Abah et al. (2014) branded that Facebook is the most popular social media site regularly used by male and female social media users. 


Table 4: Favourites social media sites between male and female

\begin{tabular}{|c|c|c|c|c|c|c|}
\hline \multirow[t]{2}{*}{ platforms } & \multicolumn{4}{|c|}{ Male } & \multicolumn{2}{|r|}{ Female } \\
\hline & Freq. & \multicolumn{3}{|l|}{$\%$} & Freq. & $\%$ \\
\hline$\overline{\mathrm{BBM}}$ & 1 & \multicolumn{3}{|l|}{0.5} & 1 & 0.7 \\
\hline Blogs & 3 & \multicolumn{3}{|l|}{1.4} & - & - \\
\hline Facebook & 148 & \multicolumn{3}{|l|}{69.2} & 88 & 62.4 \\
\hline Google Plus & 1 & \multicolumn{3}{|l|}{0.5} & 2 & 1.4 \\
\hline Instagram & 27 & \multicolumn{3}{|l|}{12.6} & 24 & 17.0 \\
\hline LinkedIn & 1 & \multicolumn{3}{|l|}{0.5} & 1 & 0.7 \\
\hline Skype & 1 & \multicolumn{3}{|l|}{0.5} & 1 & 0.7 \\
\hline Twitter & 5 & \multicolumn{3}{|l|}{2.3} & 1 & 0.7 \\
\hline WhatsApp & 25 & \multicolumn{3}{|l|}{11.7} & 21 & 14.9 \\
\hline YouTube & 2 & \multicolumn{3}{|l|}{0.9} & 2 & 1.4 \\
\hline Total & 214 & \multicolumn{3}{|c|}{100.0} & 141 & 100.0 \\
\hline \multicolumn{7}{|c|}{ Independent samples test } \\
\hline \multicolumn{2}{|l|}{ Gender } & $\mathbf{N}$ & Mean & SD & t-cal & Sig (2-tailed) \\
\hline \multicolumn{2}{|l|}{ Male } & 214 & 4.31 & 2.49 & $1.039^{*}$ & 0.299 \\
\hline \multicolumn{2}{|l|}{ Female } & \multicolumn{3}{|c|}{1414.60} & & \\
\hline
\end{tabular}

*Difference between means is insignificant at 5\% alpha level; $\mathrm{df}=353$

\subsection{Coronavirus pandemic information and type of information shared}

Respondents were asked if they have seen or come across coronavirus pandemic information on social media platforms. The result gotten is shown in Table 5. The result showed that 289 of the respondents representing $81.4 \%$ responded in the affirmative, while 66 representing $18.6 \%$ of the respondents had not seen or come across coronavirus pandemic information. It therefore implies that majority of the respondents have seen or come across information on coronavirus pandemic on social media sites. This means that social media sites are not only used for chatting, uploading of pictures and profiles, but also for sharing of health information on coronavirus pandemic. The health information shared on these sites is able to get to quite a number of students who by their ages are at the danger of the contamination due to their unguided sexual practice or inducement. In a related study, Somba et al., (2014) noted that there is high tendency of sexual activity among young people (adolescence). Similarly, Mukhopadhyay et al., (2010) stated, that "adolescent sexual behaviour is a serious health, social and demographic problem mostly in developing countries". 


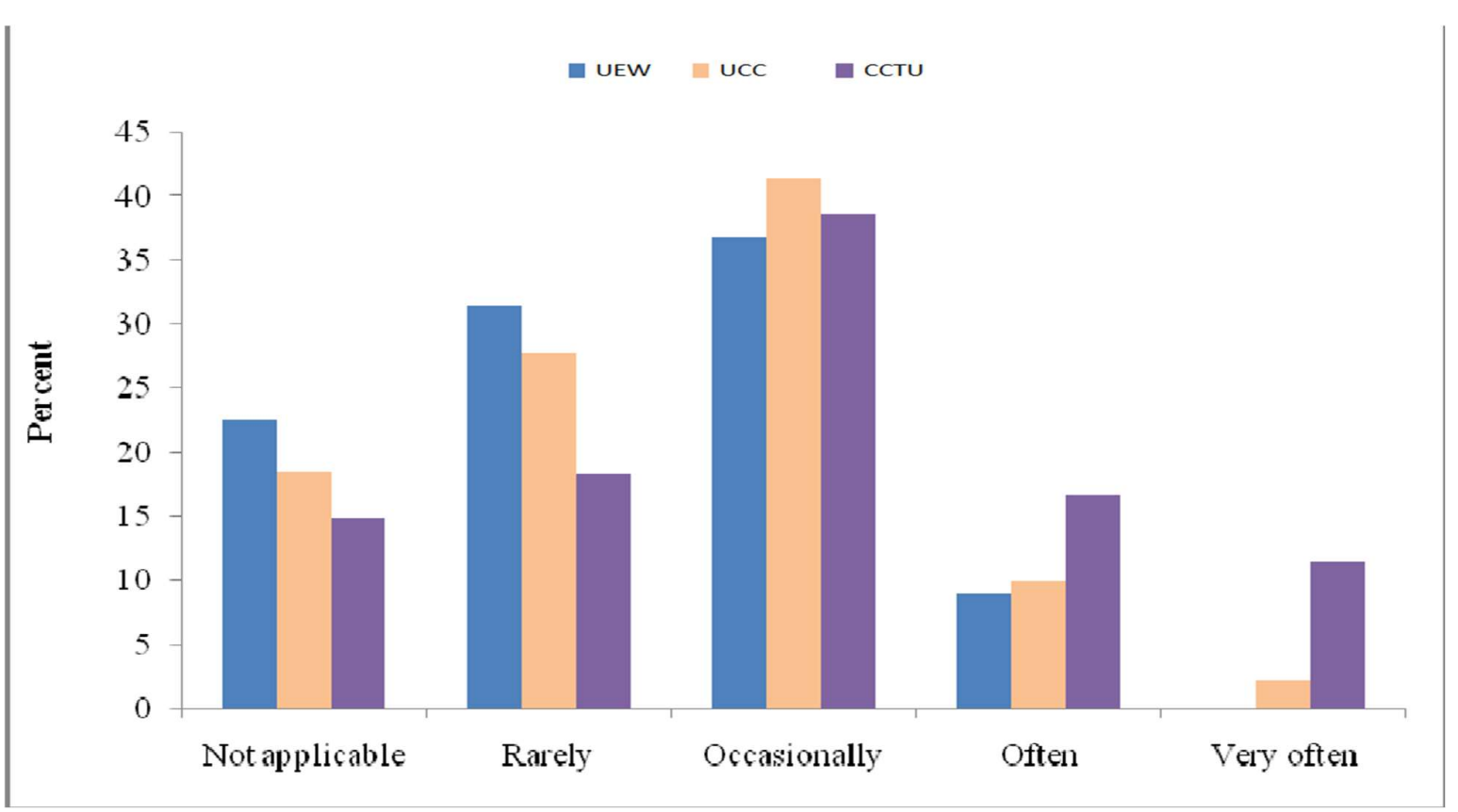

Figure 2: Frequency of seeing coronavirus pandemic information

The word termed not applicable applies to respondents who affirmed that they need not seen or encounter coronavirus pandemic information on social media platforms. Thus, the proportion of respondents who affirmed to possess seen information on coronavirus pandemic on social media platforms did so at different times (Figure2). An honest percentage $(39.2 \%)$ of them had occasionally seen such messages or information; $25.9 \%$ had rarely seen the messages; $11.8 \%$ had often seen the knowledge, while only $4.5 \%$ saw it fairly often. From the pattern that emerged, it was apparent that majority of the respondents not often or infrequently see coronavirus pandemic information on social media platform. This goes to show that health information mostly on coronavirus pandemic is shared on social media but it is hardly seen by a good proportion of social media users. This is so because out of the 289 respondents that have seen messages on coronavirus pandemic on social media sites, only $20.1 \%$ are frequently privy to such information, while the remaining percentage $(69.9 \%)$ are not frequently privy to it. this calls for the need to make coronavirus pandemic information a default message on social media platform mostly on Facebook, WhatsApp, BBM, Twitter and Instagram.

In addition, respondents were asked if they have ever shared coronavirus pandemic information on their social media site (s). Varied answers were obtained (Table 5). It showed that $24.8 \%$ of the respondents shared coronavirus pandemic information on their social media site(s), while a bigger percentage didn't share coronavirus pandemic information on their social media site (s). This clearly shows that coronavirus pandemic information isn't the type of health information people like sharing on their social media site (s). The rationale for this may be as a result of the ill-feelings and perception people attach to issues associated with coronavirus pandemic. Other health issues or information is usually tolerated and other people are always willing to read, but information on coronavirus pandemic comes with fear intrinsically it's not always shared. However, despite the negative attitude towards the disease and therefore the perception people hold towards it, only few individuals (students) were ready to share it on their social media site (s). The study therefore reveals that coronavirus pandemic information isn't usually shared by majority of the scholars on their social media site (s). It therefore means health campaign or sensitisation must be administered to enable students in tertiary institutions see the necessity to share coronavirus pandemic information on their social media sites and for college kids to ascertain coronavirus pandemic as a part of the human health challenge that must be campaigned for and to not despite it. 


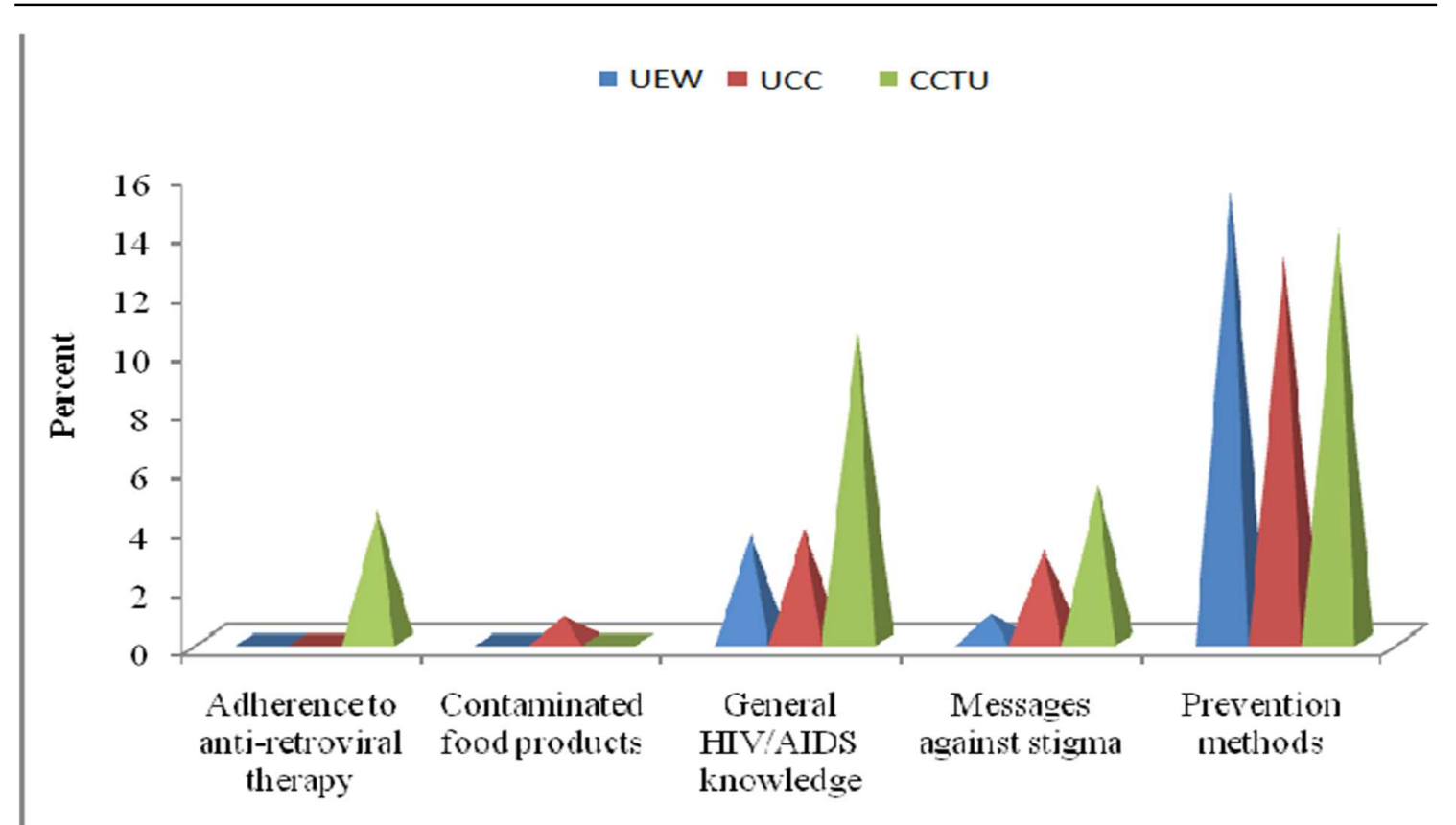

3: Types of coronavirus pandemic information shared on social media

However, the end in Table 5 identified prevention methods, followed by general coronavirus pandemic knowledge because the main sorts of information shared by those that usually share coronavirus pandemic information on their sites (Figure 3). This is often so as an honest number of the messages shared on social media platforms on coronavirus pandemic are often centred on ways to stop contracting the deadly virus. This is often so as people are more likely to read the preventive measures than see pictures of individuals infected by the virus and much more. In all, the result presented in Table 5 shows that a big proportion of the respondents across the three universities have seen or come across coronavirus pandemic information on social media and a very small percentage frequently have access or see such information. It also shows that majority of the respondents don't shared coronavirus pandemic information on their sites and for people who do, information associated with prevention methods and general coronavirus pandemic knowledge are usually shared.

Further attempt was administered by the researcher to seek out if the sort of data shared on social media sites vary across the three selected school. This was achieved using ANOVA. The analysis was performed for the category of respondents (undergraduates) that affirmed that they had shared coronavirus pandemic information on social media. The result obtained is shown in Table 6. The results of ANOVA revealed significant variation within the sort of coronavirus pandemic information shared on social media among the schools $(F=5.177 ; p<0.05)$.

This is apparent as undergraduates in the three universities did not share similar types of coronavirus pandemic information. A look at the summary of result in Table 5 showed that undergraduates in Cape Coast Technical University and University of Cape Coast shared four types of coronavirus pandemic information and those in University of Education-Winneba shared three of such information. Though, prevention methods and general knowledge of coronavirus pandemic were prominent information shared on social media. In Cape Coast Technical University, apart from the two coronavirus pandemic information, a non-negligible number of undergraduates also shared information on adherence to anti-retroviral therapy and messages against stigma. It can therefore be deduced that undergraduates in Cape Coast Technical University shared more coronavirus pandemic information on social media followed by those in University of Cape Coast and then University of Education, Winneba. Furthermore, result of Post Hoc Test of multiple comparison of type of coronavirus pandemic information shared between the universities using the Least Square Difference (LDS) indicated that type of coronavirus pandemic information shared in University of Education, Winneba did not fifer significantly from those shared by undergraduates in University of Cape Coast but differed significantly with those shared in Cape Coast Technical University (Table 2). Also, the type of coronavirus pandemic information shared in University of Cape Coast differed significantly with those shared in Cape Coast Technical University but did not differ significantly with those shared in University of Education, Winneba; whereas, the type of coronavirus pandemic information shared in Cape Coast Technical University differed significantly from those shared in University of Education, Winneba and University of Cape Coast respectively. 
Table 5: coronavirus pandemic information and type of information shared

\begin{tabular}{|c|c|c|c|c|c|c|c|}
\hline \multirow[t]{4}{*}{ Variables } & \multicolumn{4}{|c|}{ Universities } & \multicolumn{2}{|l|}{ Total } & \\
\hline & \multicolumn{2}{|c|}{ UEW } & \multicolumn{2}{|c|}{$\mathrm{UCC}$} & \multicolumn{2}{|c|}{ CCTU } & \\
\hline & \multicolumn{2}{|c|}{$\%$} & \multirow[b]{2}{*}{$\begin{array}{l}\text { Freq } \\
(n=130)\end{array}$} & \multirow[b]{2}{*}{$\begin{array}{l}\% \\
(100)\end{array}$} & \multirow[b]{2}{*}{$\begin{array}{l}\text { Freq } \\
(n=114)\end{array}$} & \multirow[b]{2}{*}{$\begin{array}{l}\% \\
(100)\end{array}$} & \\
\hline & $\begin{array}{l}\text { Freq } \\
(n=111)\end{array}$ & $\begin{array}{l}\% \\
(100)\end{array}$ & & & & & \\
\hline \multicolumn{8}{|c|}{ Ever seen coronavirus pandemic information? } \\
\hline Yes & 86 & 77.5 & 106 & 81.5 & 97 & 85.1 & 81.4 \\
\hline No & 25 & 22.5 & 24 & 18.5 & 17 & 14.9 & 18.6 \\
\hline $\begin{array}{l}\text { If Yes, how often? } \\
\text { Not applicable }\end{array}$ & 25 & 22.5 & 24 & 18.5 & 17 & 14.9 & 18.6 \\
\hline Rarely & 35 & 31.5 & 36 & 27.7 & 21 & 18.4 & 25.9 \\
\hline Occasionally & 41 & 36.9 & 54 & 41.5 & 44 & 38.6 & 39.2 \\
\hline Often & 10 & 9.0 & 13 & 10.0 & 19 & 16.7 & 11.8 \\
\hline Very often & - & - & 3 & 2.3 & 13 & 11.4 & 4.5 \\
\hline Ever shared & & & & & & & \\
\hline $\begin{array}{l}\text { information } \\
\text { Yes }\end{array}$ & 22 & 19.8 & 27 & 20.8 & 39 & 34.2 & 24.8 \\
\hline No & 89 & 80.2 & 103 & 79.2 & 75 & 65.8 & 75.2 \\
\hline \multicolumn{8}{|l|}{ If Yes, type of information shared } \\
\hline Not applicable & 89 & 80.2 & 103 & 79.2 & 75 & 65.8 & 75.2 \\
\hline Adherence to anti-retroviral therapy & - & - & - & - & 5 & 4.4 & 1.4 \\
\hline Contaminated food products & - & - & 1 & .8 & - & - & .3 \\
\hline General coronavirus pandemic knowledge & 4 & 3.6 & 5 & 3.8 & 12 & 10.5 & 5.9 \\
\hline Messages against stigma & 1 & .9 & 4 & 3.1 & 6 & 5.3 & 3.1 \\
\hline Prevention methods & 17 & 15.3 & 17 & 13.1 & 16 & 14.0 & 14.1 \\
\hline
\end{tabular}

This therefore means that Cape Coast Technical University shares more coronavirus pandemic information on social media than the other two universities.

\section{References}

Abah, R. C., Aderibigbe, T. \& Olubunmi, A. (2014) Importance of social media in engaging young people on Human Immunodeficiency Virus (HIV) prevention. Journal of AIDS \& HIV Research, 6 (8): 152 - 159.

Antino Kim, Patricia L. Moravec \& Alan R. Dennis (2019) Combating Fake News on Social Media with Source Ratings: The Effects of User and Expert Reputation Ratings, Journal of Management Information Systems, 36:3, 931-968, DOI: 10.1080/07421222.2019.1628921.

Boyd, D.M., and Ellison, N.B. (2007) Social network sites: Definition, history, and scholarship. Journal of Computer-Mediated Communication, 13(1).

Bruno Kessler Foundation. (2020). Fake news in the time of C-19. Available at: https://members.tortoisemedia.com/2020/03/23/the-infodemic-fake-newscoronavirus/content.html (Accessed April 27, 2020).

Centers for Disease Control and Prevention, (2015). Severe Acute Respiratory Syndrome (SARS)

Cinelli M, Cresci S, Galeazzi A, Quattrociocchi W, Tesconi M (2020). The limited reach of fake news on Twitter during 2019 European elections. PLoS ONE 15(6): e0234689. https://doi.org/10.1371/journal.pone.0234689

Dlamini, C., Ncube, F. and Muchemwa, S. (2015). The use of social media technology in universities: A case of Solusi University, Zimbabwe. Journal of Media and Communication Studies, 7(5): 101-111. 
Economic and Social Research Council Using Social Mmedia. [(Accessed on 20 April 2020)]; Available online: https://esrc.ukri.org/research/impact-toolkit/social-media/using-social-media/.

Ferguson, M. (2002). The mythology about globalization. In D. Mcquail (Ed.), Mcquail's reader in mass communication theory (pp. 238-248). London: Sage Publications Ltd.

Harapana H., Itohd N., Yufika A., Winardif W., Keamg S., Te H. Coronavirus disease 2019 (COVID-19): A literature review. J Infect Pub Health. 2020;13:667-673. doi: 10.1016/j.jiph.2020.03.019.

Hoffman, D. \& Novak, T. (2012). Towards a deeper understanding of social media. Journal of Interactive Marketing.

Idubor, I., (2015) Investigating social media usage and addiction levels among undergraduates in University of Ibadan, Nigeria. British Journal of Education, Society \& Behavioural Science, 7(4): 291-301.

Kaplan, A. M. and Haenlein, M. (2010) Users of the world, unite! The challenges and opportunities of social media. Business Horizons, 53(1): 59-68.

Lee, N., Hui, D., Wu, A., Chan, P., Cameron, P., Joynt, G.M., Sung, J.J., 2003. A major outbreak of severe acute respiratory syndrome in Hong Kong. N. Engl. J. Med. 348 (20), 1986-1994.

Liu J, Liao X, Qian S et al (2020). Community transmission of severe acute respiratory syndrome coronavirus 2 , Shenzhen, China, 2020. Emerg Infect Dis 2020 doi.org/10.3201/eid2606.200239.

Lowell C., Matthews \& Bharat Thakkar (2012). The Impact of Globalization on Cross-Cultural Communication. [(accessed on 15 June, 2020)]; Available online: https://creativecommons.org/licenses/by/3.0/.

Luo G, Gao SJ. (2020), Global Health Concern stirred by emerging viral infections. J Med Virol. doi: 10.1002/jmv.25683.

Mangold, W.G., Faulds, D.J. (2009) Social media: the new hybrid element of the promotion mix. Business Horizons, 52(1) 357-365.

Mazman, S. G. \& Usluel, Y. K. (2011) Gender differences in using social networks. TOJET: The Turkish Online Journal of Educational Technology, 10 (2): 133 - 139.

Mukhopadhyay, P., Chaudhuri, R. N. and Bhaskar, P. (2010) Hospital-based Perinatal Outcomes and Complications in Teenage Pregnancy in Tanzania. J. Health Popul Nutr, 28 (5):494 - 500.

Musa, A. S., Azmi, M. N. L. and Ismail, N S. (2015) Awareness and usage of social media: a study of mass communication students of Kano state polytechnic. International Conference on Languages | ICL 2015 Kuala Lumpur. 15p

Ndeti, N. (2013) Interpersonal communication and HIV AND AIDS: Influencing behavioral responses to HIV amongst students in Nairobi. Nairobi: Nairobi Academic Press. 140p

Owusu-Acheaw, M. and Larson, A.G (2015). Use of social media and its impact on academic performance of tertiary institution students: A study of students of Koforidua Polytechnic, Ghana. Journal of Education and Practice, 6 (6) 94-101.

Peiris M. and Guan Y. (2004). Confronting SARS: a view from Hong Kong. The Royal Society. DOI: 10.1098/rstb.2004.1482 - Source: PubMed

Pempek, T. A., Yermolayeva, Y. A. \& Calvert, S. L. (2009) College students' social networking experiences on Facebook. Journal of Applied Developmental Psychology, 30 (3), 227-238.

Prajapat M., Sarma P., Shekhar N., Avti P., Sinha S., Kaur H., Kumar S., Bhattacharyya A., Kumar H., Bansal S. (2020). Drug targets for corona virus: a systematic review, Indian J. Pharmacol. 52 (1) 56.

Rosen, D., Stefanone, M. A., \& Lackaff, D. (2010) Online and offline social networks: Investigating culturallyspecific behavior and satisfaction. In Proceedings of the 43rd Hawai i International Conference on System Sciences. New Brunswick: Institute of Electrical and Electronics Engineers, Inc. (IEEE).

Rothman KJ, Lash T, Greenland S. (2013). Modern Epidemiology (3 ${ }^{\text {rd }}$ ed.), Lippincott Williams \& Wilkins.

Somba, M. J., Mbonile, M., Obure, J. and Mahande, M. J. (2014) Sexual behaviour, contraceptive knowledge and use among female undergraduates' students of Muhimbili and Dares Salaam Universities, Tanzania:a cross-sectional study. Retrieved from: https://www.ncbi.nlm.nih.gov/pmc/articles/PMC4126911/pdf/1472-6874-14-94.pdf

Singhal T., (2020). A review of coronavirus disease (COVID-19). Indian J. Pediatr. 1-6.

Swidan, A., Al-Shalabi, H., Jwaifell, M., Awajan, A. and Alrabea, A. (2013) The intensity and the factors affecting the use of social network sites among the students of Jordanian universities. International Journal of Computer Science Issues, 10 (3): 492 - 498.

Tandoc, E. C. Jr., Lim, Z. W., \& Ling, R. (2018). Defining "fake news": A typology of scholarly definitions. Digital Journalism, 6(2), 137-153. doi:10.1080/21670811.2017.1360143. 
Tian X, Li C, Huang A, Xia S, Lu S, Shi Z. Potent binding of 2019 novel coronavirus spike protein by a SARS coronavirus-specific human monoclonal antibody. Emerg Microbes Infect. 2020;9:382-385. doi: 10.1080/22221751.2020.1729069.

The role of social media during a pandemic. Khoros. 2020. Available from: https://khoros.com/blog/social-mediasrole-during-covid-19 [cited Apr 16th, 2020].

Tukru, B. and Abdukadir, G. (2013) Facebook addiction among university students in Turkey Selcuk university example. Journal of Turkish Studies, 34:255.

UN News. (2020). During this coronavirus pandemic, 'fake news' is putting lives at risk: UNESCO. Available at: https://news.un.org/en/story/2020/04/1061592 (Accessed June 27, 2020).

Waszak P.M., Kasprzycka-Waszak W., \& Kubanek A. The spread of medical fake news in social media-The pilot quantitative study. Health Policy Technol. 2018; 7:115-118. doi: 10.1016/j.hlpt.2018.03.002.

WHO, (2020). Update on MERS-CoV transmission from animals to humans, and interim recommendations for atrisk groups. WHO June 2020. <http://www.dailymail.co.uk/news/article-2332677/ WHO-calls-MiddleEastern-virus-MERS-threat-entire-world-deathtoll-rises-27.html>.

WHO, (2020). WHO concludes MERS-CoV mission in Saudi Arabia, May 2020. Available: <http://www. emro.who.int/media/news/mers-cov-mission-saudi-arabia.html $>$ (accessed 09.08.14).

WHO, (2020). Coronavirus disease 2019 (COVID-19) Situation Report - 59. Available online: https://www.who.int/docs/default-source/coronaviruse/situation-reports/20200319-sitrep-59-covid19.pdf?sfvrsn=c3dcdef9 2 .

WHO. (2019) New Hope with Ebola Drug Trial. ; [(accessed on 20 June, 2019)]; Available online: https://www.afro.who.int/news/new-hope-ebola-drug-trial.

Wuhan Municipal Health Commission (2019) Report of clustering pneumonia of unknown etiology in Wuhan City. http://wjw.wuhan.gov.cn/front/web/showDetail/2019123108989 [in Chinese]. 